\title{
Ultrastructure of myocardium in familial heart - block and peroneal muscular atrophy
}

\author{
J. M. Kay ${ }^{1}$, W. A. Littler ${ }^{2}$, and J. B. Meade
}

From the Department of Pathology, University of Liverpool, and

the Regional Cardiothoracic Centre, Broadgreen Hospital, Liverpool

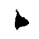

A myocardial biopsy specimen from a 42-year-old man with familial heart block and peroneal muscular atrophy revealed ultrastructural changes similar to those previously described in simple myocardial hypertrophy and hypertrophic obstructive cardiomyopathy. These consisted of the

- formation of cardiac 'villi' crowded with mitochondria, enhanced micropinocytosis, and vacuola-

$\therefore$ tion of the sub-sarcolemmal cytoplasm.

Peroneal muscular atrophy (Charcot-MarieTooth disease) is a slowly progressive neurogenic atrophy affecting mainly the distal

- muscles of the legs and sometimes the intrinsic muscles of the hands. It may be trans-

- mitted, in different families, by autosomal dominant, autosomal recessive, $\mathrm{X}$-linked dominant, and $\mathrm{X}$-linked recessive modes of inheritance. In a previous paper, one of us described a family in which both heart block 4 and peroneal muscular atrophy were present (Littler, 1970). Ten members of three generations were affected. Heart block and peroneal muscular atrophy occurred together in 3

cases; 6 patients had right bundle-branch block alone; peroneal muscular atrophy without conduction defect occurred in one instance. The aetiology of the cardiac disease remained obscure despite many investiga- tions.

Recently, we obtained a biopsy specimen

- of heart muscle from one of the patients with peroneal muscular atrophy and heart block,

- and examined this with the electron microscope.

\section{- Case report}

The propositus of the original study (Littler, - 1970) was a man aged 4I years who had suffered from claw feet since childhood and had noticed atrophy of the lower part of his legs for several years. When aged 39 he had complained of dizziness, and an electrocardiogram revealed sinus

- 1 Present address: Cardiovascular Pulmonary Research Laboratory, University of Colorado Medical Center, 4200 East Ninth Avenue, Denver, Colorado 80220, U.S.A.

> 2 Present address: Department of Medicine, The Radcliffe Infirmary, Oxford. bradycardia together with right bundle-branch block and left axis deviation. At the age of 4I he was admitted to hospital after a sudden loss of consciousness which lasted for several minutes.

Examination revealed a heart rate of 38 a minute, systemic blood pressure $180 / 80 \mathrm{mmHg}$, and the physical signs of complete heart block. His legs showed pronounced wasting of the peroneal muscles and bilateral pes cavus. The knee-jerks were diminished and the ankle-jerks absent. The plantar responses were equivocal and other tendon reflexes normal. There was no sensory disturbance or cerebellar dysfunction and the optic discs were normal.

Electromyography of the peroneal muscles revealed the pattern of chronic denervation. Electrocardiography showed complete heart block with a right bundle-branch pattern. Investigations into the cause of the heart block were unrewarding. These included blood Wassermann reaction; estimations of serum aspartate aminotransferase (SGOT), serum alanine aminotransferase (SGPT), and lactic dehydrogenase (LDH); serum uric acid; serum aldolase and creatine phosphokinase; rheumatoid and antinuclear factors; viral antibody titres; a Kveim test; and a rectal biopsy for amyloid.

An Adams-Stokes attack due to asystole was witnessed shortly after admission. The patient was initially treated with oral prednisolone and isoprenaline. For a short time the pattern of conduction varied between different degrees of atrioventricular block, with ventricular rates attaining 60 a minute. Eventually he settled into a stable complete heart block which was resistant to drug therapy.

The patient was free from symptoms for 9 months, but then developed 'dizzy turns' which lasted up to one minute and occurred two or three times a day. The attacks were considered to be Adams-Stokes seizures and the patient was advised to have an artificial pacemaker. The wires of a Birmingham (Lucas) inductive coupled coil 
cardiac pacemaker were implanted into the heart at thoracotomy and a myocardial biopsy specimen was taken from the anterior wall of the left ventricle during the operation.

\section{Pathology}

Methods The myocardial biopsy specimen was divided into two portions. The first portion was fixed in ice-cold glutaraldehyde for electron microscopy. This tissue was subsequently postfixed in osmium tetroxide, stained with uranyl acetate, and embedded in araldite. Ultra-thin sections were stained with lead citrate, mounted on copper grids, and examined in an EM6B electron microscope. The remaining portion of tissue was fixed in buffered neutral formalin and routinely processed for light microscopy.

Light microscopy The epicardium, myocardium, and interstitial tissues appeared normal.

Electron microscopy The heart muscle cells showed a relatively normal internal structure but the sarcolemma and sub-sarcolemmal cytoplasm were abnormal.

The muscle cells contained normal longitudinally oriented myofibrils separated from one another by columns of mitochondria (Fig. I). Each myofibril showed the normal pattern of cross striation produced by the interdigitation and regular overlapping of its constituent parallel thick and thin filaments.

The muscle cells were delimited by a thin membrane called the sarcolemma which was itself bounded externally by a thin granular basement membrane. The borders of the heart muscle cells presented a 'saw-toothed' or scalloped contour due to the protrusion of numerous finger-like processes or villi from the cell surface into the adjacent interstitial spaces (Fig. r). The sub-sarcolemmal cytoplasm of these cardiac villi was packed with mitochondria. Numerous micropinocytic vesicles at different stages of formation were seen in relation to the sarcolemma. Some of the villi contained large clear vacuoles (Fig. 2). Large, irregular electron-dense lipofuscin granules were located at either end of the elongated nucleus, and occasionally in the subsarcolemmal cytoplasm (Fig. 3).

\section{Discussion}

In normal cardiac muscle fibres the basement membrane and underlying sarcolemma infold at the region of the $Z$ line; the degree of infolding is proportional to the degree of contraction of the underlying myofibrils (Stenger and Spiro, 1961). Mitochondria are sometimes found under the sarcolemma in normal heart muscle, and when they do occur their presence enhances the arcade-like appearance of the sarcolemma which occurs in contraction because of its attachment to the $Z$ line. The

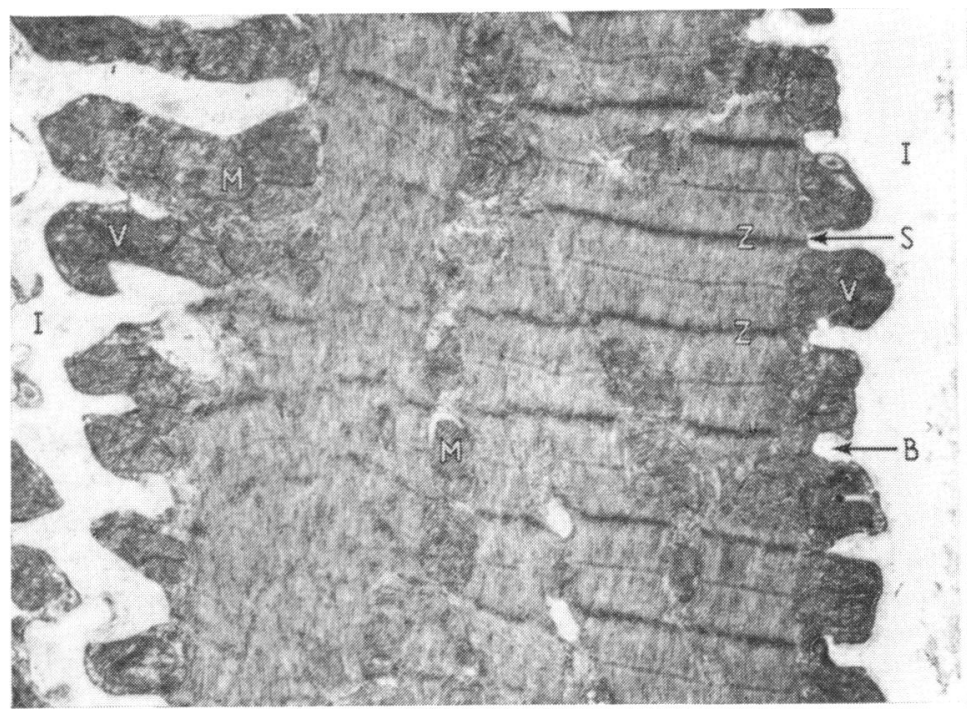

FI I I Longitudinal section of cardiac muscle cell. Finger-like processes (cardiac villi $(V))$ protrude into interstitial space (I) producing $a$ 'saw-toothed' appearance of the cell borders. Note granular basement membrane $(B)$ and regular infolding of sarcolemma $(S)$ in region of $Z$ line $(Z)$. Mitochondria $(M)$ are located between myofibrils and in sub-sarcolemmal cytoplasm of cardiac villi. (Electron micrograph. $\times 8250$.)

finger-like projections of sarcolemma or cardiac 'villi' which we observed in the present case are probably a gross exaggeration of the normal scalloped contour related to a proliferation of mitochondria in the sub-sarcolemmal cytoplasm.

The changes in this cardiac muscle biopsy specimen, namely the formation of cardiac villi, proliferation of mitochondria, and vacuolation of the sub-sarcolemmal cytoplasm, together with enhanced sarcolemmal micropinocytosis, are similar to the ultrastructural findings in human cardiac muscle hypertrophy. Poche (1960) described a 'diverticulosis' of the sarcolemma occurring in the atrial myocardium of patients with mitral stenosis. It was regarded as a manifestation of cardiac muscle hypertrophy. The term 'cardiac villi' was introduced by Dowlatshahi and Hunt (1969) who carried out an ultrastructural study of ventricular myocardium in cases of cardiac hypertrophy due to outflow tract stenosis. They described finger-like protrusions from the cell surfaces into the interstitial space. These cardiac 'villi' were crowded with mitochondria and showed active pino- 


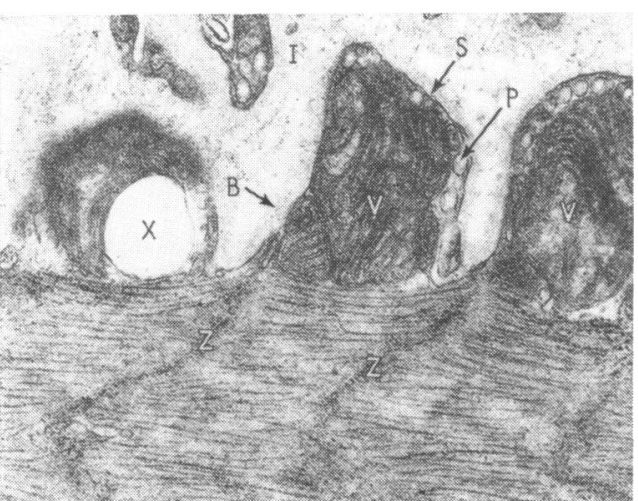

FIG. 2 Longitudinal section of edge of cardiac muscle cell showing three cardiac villi $(V)$ projecting into interstitial space (I). Each villus is delimited by the sarcolemma $(S)$ and is packed with mitochondria. One villus contains a large vacuole $(X)$. Several micropinocytic vesicles $(P)$ are situated just beneath the sarcolemma. Note $Z$ lines $(Z)$ and granular basement membrane (B). (Electron micrograph. $\times 22500$.)

FIG. 3 Longitudinal section of heart muscle cell showing dark lipofuscin granules $(L)$ situated near nucleus $(N)$ and in sub-sarcolemmal cytoplasm. Note cardiac villi $(V), Z$ lines $(Z)$, and sarcolemma $(S)$. (Electron micrograph. $\times 4500$.)

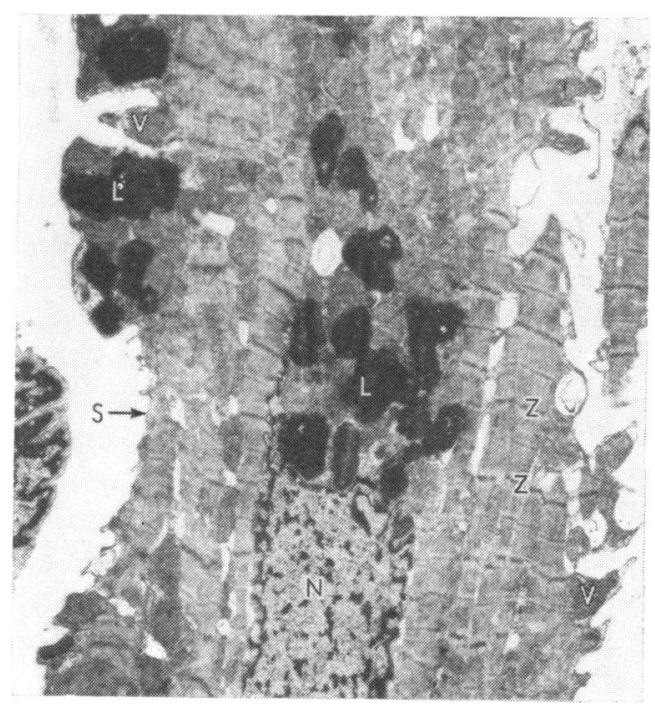

cytosis on their surface; some contained vacuoles apparently formed by coalition of pinocytic vesicles. It was postulated that the formation of villi indicated the need of the hypertrophied cell for an increased absorptive surface.

Cardiac villi have also been recognized in surgically resected tissue from the hearts of patients with hypertrophic obstructive cardiomyopathy (Meessen and Poche, 1967; Van Noorden, Olsen, and Pearse, I971).

Our patient may have developed myocardial hypertrophy secondary to increased left ventricular work associated with increased left ventricular diastolic volume caused by complete heart block with bradycardia. It is possible that the ultrastructural changes we observed were a manifestation of cardiac hypertrophy.

Peroneal muscular atrophy does not usually affect the heart. Leak (I96I) suggested that a case of paroxysmal atrial flutter in a patient with peroneal muscular atrophy might have been caused by neurological involvement of the heart. Apart from this case, the present family seems to be the only one where there is well-documented evidence of both cardiac and neurological involvement. Roth (1948) described a family in which there was a possible relation between hereditary ataxia and peroneal muscular atrophy, and found that 5 of the 15 members had 'heart disease'. Of these 5 , one had died aged 62 years of a heart attack, and another of rheumatic heart disease aged 34 years. The exact nature of the cardiac lesion in the other 3 was not known and electrocardiograms were not recorded.

There are several other neurological disorders with a familial incidence which are associated with heart muscle disease (Hudson, 1969). In Friedreich's ataxia the electrocardiogram is abnormal soon after the onset of neurological signs, and two-thirds of patients die a cardiac death (Graham, 1964). Necropsy reveals extensive replacement fibrosis of the myocardium. Refsum's disease is a recessively inherited lipid storage disorder in which phytanic acid is deposited in the heart, nerves, and other tissues (Hudson, 1969). In certain types of hereditary amyloidosis, deposits of amyloid are found in the heart and nervous system (Andersson, 1970).

It would be convenient to place our family into the group of neurological diseases with associated cardiomyopathy. However, one point against this is the occurrence of the conduction defects without any associated neurological disease in several of the patients; the possible genetic explanations have already been discussed elsewhere (Littler, I970). 
We are grateful to Dr. C. S. McKendrick and Mr. J. K. B. Waddington for permission to study their patient.

\section{References}

Andersson, R. (1970). Hereditary amyloidosis with polyneuropathy. Acta Medica Scandinavica, 188, 85.

Dowlatshahi, K., and Hunt, A. C. (1969). Electron microscopical findings in hypertrophied human ventricle. British Heart fournal, 31, 200.

Graham, G. R. (1964). Friedreich's disease. In Ciba Foundation Symposium: Cardiomyopathies, pp. 358370. Ed. by G. E. W. Wolstenholme and M. O'Connor. Churchill, London.

Hudson, R. E. B. (1969). Familial heart disease. British Heart fournal, 31, I43.

Leak, D. (I96I). Paroxysmal atrial flutter in peroneal muscular atrophy. British Heart fournal, 23, 326.

Littler, W. A. (1970). Heart block and peroneal muscular atrophy. A family study. Quarterly fournal of Medicine, 39, 431 .

Meessen, H., and Poche, R. (1967). Beiträge zur pathologischen Anatomie der Fallotschen Fehler und zur idiopathischen Herzhypertrophie. AngloGerman Medical Review, 4, 73.

Poche, R. (1960). Die Submicroskopische Morphologie des Herzmuskelzelle unter Pathologischen Bedingungen. In Acta Tertii Europaei de Cordis Scientia Conventus, Roma, Pars prior pp. 99-I09. Excerpta Medica, Amsterdam.

Roth, M. (1948). On a possible relationship between hereditary ataxia and peroneal muscular atrophy; with a critical review of the problems of 'intermediate forms' in the degenerative disorders of the central nervous system. Brain, 71, 416.

Stenger, R. J., and Spiro, D. (I96I). Structure of the cardiac muscle cell. American fournal of Medicine, 3o, 653 .

Van Noorden, S., Olsen, E. G. J., and Pearse, A. G. E. (I97I). Hypertrophic obstructive cardiomyopathy, a histological, histochemical, and ultrastructural study of biopsy material. Cardiovascular Research, 5 , I 18.

Requests for reprints to Dr. J. M. Kay, Department of Pathology, P.O. Box I47, Liverpool L69 3BX.

\section{IVth International Symposium on Cardiac Pacing}

The IVth International Symposium on Cardiac Pacing is to be held in Groningen, The Netherlands, 17-19 April 1973. It is intended that the scientific programme will consist of sections on basic principles of cardiac stimulation, cardiac pacing and pacing systems throughout the world, energy sources, electrodes, stimulation threshold, pacing in myocardial infarction, pacemaker clinics, and follow-up systems.

Further details can be obtained from the Secretariat, Symposium on Cardiac Pacing, Department of Cardiology, University Hospital, Groningen, The Netherlands. 